\title{
DOCUMENTOS
}




\section{EL MANIFIESTO DE CORDOBA PRESENTACION}

Por Augusto Franco Arbelaez*

Tal vez ningún documento universitario suramericano ha tenido tanta resonancia mundial como el Movimiento de Córdoba y en especial el Manifiesto del 21 de junio de 1918. Casi podría afirmarse que él contiene el mensaje ideológico latinoamericano sobre lo que deberá ser la Universidad. Desafortunadamente al cotejarlo con la realidad más común que se vive en nuestras universidades, gran parte de los vicios denunciados en la Universidad de Córdoba (Argentina) siguen nublando el panorama universitario de nuestro continente.

Frente a los modelos universitarios de Europa y Estados Unidos, Córdoba representó la exigencia de la participación estudiantil no sólo a nivel del aprendizaje como que "toda la educación es una larga obra de amor a los que aprenden ", sino muy especialmente a nivel de las decisiones institucionales. Ese credo del DEMOS universitario si bien les resultó peregrino en 1918, hoy día sería un pedido por demás natural ante el crecimiento de la conciencia estudiantil y universitaria sobre la necesidad de la participación de los alumnos aun a nivel de Consejos Universitarios.

Córdoba fue un grito de independencia contra el dominio profesoral de los ineptos y de los dogmáticos. Córdoba representó una nueva concepción institucional universitaria como un hogar de estudiantes y dejó como ideal para todas las generaciones esa gran pedagogía representada por aquella parte del Manifiesto que dice:

“...La autoridad, en un hogar de estudiantes, no se ejercita mandando, sino sugiriendo y amando: enseñando.

Si no existe una vinculación espiritual entre el que enseña y el que aprende, toda enseñanza es hostil y de consiguiente infecunda..."180.

Muchos son los estudiantes y profesores universitarios que se refieren al Manifiesto como una apología al co-gobierno y al sistema de democracia política aplicada a la universidad, olvidando los bellos aportes pedagógicos y el ideal del genuino maestro $y$ profesor que se encuentran plasmados en dicho documento.

Como con frecuencia es difícil encontrar el texto del 21 de junio, éste se transcribe en las páginas siguientes, como una contribución a la discusión universitaria tan importante en nuestros días. Lo nuevo y lo antiguo ha de conjugarse para lograr el equilibrio en el devenir diario de nuestros claustros.

\footnotetext{
* Ph. D. en Educación. Especialista en Planeación Educativa. M.A. en Desarrollo Económico Rector de la Universidad Pedagógica Nacional.

${ }^{180}$ Tunnermann Carlos. Sesenta años de la Reforma Universitaria de Córdoba. 1918-1978. Primera Edición. EDUCA, Centroamérica, San José, Costa Rica, 1978. Págs. 67-73. 